\title{
Transcanal Endoscopic Ear Surgery with Piezoelectric Device for External Auditory Canal Lesions
}

\author{
Chan Young Lee $\mathbb{D}^{\mathbb{D}}$, Seung Ho Kim $\mathbb{D}^{\mathbb{D}}$, and Jeong Hwan Choi $\mathbb{1}$ \\ Department of Otorhinolaryngology-Head and Neck Surgery, Inje University Sanggye Paik Hospital, Seoul, Korea
}

\author{
Piezoelectric Device를 이용한 외이도 병변에 대한 이내시경 수술 \\ 이찬영 · 김승호 · 최정환 \\ 인제대학교 의과대학 상계백병원 이비인후과학교실
}

\author{
Received December 15, 2020 \\ Revised February 26, 2021 \\ Accepted March 22, 2021 \\ Address for correspondence \\ Jeong Hwan Choi, MD \\ Department of Otorhinolaryngology- \\ Head and Neck Surgery, \\ Inje University \\ Sanggye Paik Hospital, \\ 1342 Dong Il-ro, Nowon-gu, \\ Seoul 01757, Korea \\ Tel +82-2-950-1104 \\ Fax $+82-2-935-6220$ \\ E-mail choijh92@paik.ac.kr
}

External auditory canal exostosis (EACE) is prone to occur in patients frequently exposed to cold water, which causes earwax impaction, recurrent otitis externa, and conductive hearing loss. The main treatment for symptomatic EACE is surgical excision. External auditory canal cholesteatoma (EACC) is a bone-destructive cystic mass caused by accumulation of plugs of desquamated keratin debris in the external auditory canal (EAC), which is also mainly treated with surgical removal. The main difficulties in the surgical removal of obstructive EACEs or EACCs are related to the adjacency of EAC skin, tympanic membrane, temporomandibular joint, and the blockage of the medial EAC landmarks during the operation. The piezoelectric device (PZD), which has long been used to cut bony structures in dental surgery, has clinical advantages here with regards to accurate exclusive bone cutting ability and minimal heat production. We report a series of cases that managed EAC lesions using PZD.

Korean J Otorhinolaryngol-Head Neck Surg 2021;64(7):511-6

Key Words Cholesteatoma $\cdot$ Ear canal $\cdot$ Exostoses $\cdot$ Piezosurgery.

\section{Introduction}

Exostosis is a rare condition, characterized by a benign bony growth extending outwards from the surface of a bone. External auditory canal exostosis (EACE) is benign hyperplasia of the lamellar bone secondary to chronic thermal, physical, or chemical irritation. It is well known to have a high prevalence in frequent cold water exposurers such as surfers or divers. ${ }^{1)}$ EACE, or surfer's ear, has broad base and is multiple, unlike osteoma which is a pedunculated solitary bony tumor. It is usually asymptomatic at the beginning, but as it grows, external auditory canal (EAC) obstruction, conductive hearing loss, or even cholesteatoma might occur. Symptomatic EACE

This is an Open Access article distributed under the terms of the Creative Common Attribution Non-Commercial License (https://creativecommons.org/licenses/by-nc/4.0) which permits unrestricted non-commercial use, distribution, and reproduction in any medium, provided the original work is properly cited. can be managed surgically. The surgery consists of complete EACE removal and the restoration of EAC skin.

External auditory canal cholesteatoma (EACC) is a rare condition in which keratin materials accumulate in the EAC and form a bone-destructive cystic mass. Small lesions can be managed conservatively, whereas larger lesions with symptoms such as otalgia and otorrhea need surgery, which consists of removing the cholesteatoma and reconstructing the defect site. $^{2)}$

Until now, bony structures in otologic surgery have been cut by motorized drills with customized tips for efficient bone cutting or grinding. However, motorized instruments are prone to produce large amounts of heat which results in burning and consequential delayed bone healing. ${ }^{3)}$ During the drilling, the neighboring soft tissues may get caught in the rotating burr. Resultant skin loss and bare bone exposure delay healing and 
may require additional procedures such as skin graft.

To reduce the heat production, rotational speed should be controlled. However, lowering the speed hinders the cutting action. To compensate for the low-rotation speed, the surgeon should increase manual pressure, which consequently results in augmented macrovibrations and low surgical sensitivity.

The complications of drilling also include noise induced hearing loss, perforation of the tympanic membrane (TM) and EAC stenosis. The aforementioned problems promoted the development of the new instruments that are capable of cutting the bone with minimal heat production without adjacent tissue injury.

After considering all of the innovative items, we decided to perform transcanal endoscopic ear surgeries (EES) with piezoelectric device (PZD) for EACE or EACC. This relatively new device is based on ultrasonic microvibrations. ${ }^{4)}$ The passage of electric currents across certain ceramics transforms the structures of the device to produce microvibration.

The main advantage of the PZD was the absence of macrovibration so that the accurate and safe bone dissection would be possible. The absence of any rotating parts in the device also allowed us to use the cottonoid for protecting the EAC skin without annoying spooling and even to contact directly between the PZD tip and EAC skin.

Recently, EES has been extensively used in the field of otology as a minimally invasive procedure, allowing the entire view and complete resection of the EAC lesions. The use of a PZD in the treatment of EACE has been reported in only one English literature. ${ }^{5)}$ In this report, we present case series of EACE and EACC that were safely treated by EES with PZD.

\section{Case}

\section{Case 1}

A 41-year-old male patient presented with a several-year history of slow growing masses in the left EAC. He had been operated for right EACE 5 years ago by postauricular approach under the view of microscope. At that time, he had decided to remove the larger right EACE first. He re-visited the clinic for the purpose of removing the remaining left EACE. Painless, even-surfaced hard masses were observed in the left bony EAC (Fig. 1A). Although the surgery was not indicated as the patient was asymptomatic, he strongly wanted to have the surgery before going abroad for years, where proper management of EACE was not expected. The computed tomography of temporal bone (TBCT) revealed about $4 \mathrm{~mm}$-sized bony protru- sions at anterosuperior wall of left EAC (Fig. 1B). The broad based bony proliferations were consistent with exostosis. During the following operation, the skin of EAC was infiltrated with 2 percent lidocaine and 1:100000 epinephrine. After making several circumferential incisions along the masses, skin flaps were elevated using round knife and duckbill elevator as laterally based flaps for the lateral surface of the each mass and medially based flaps for the medial side. ${ }^{5}$ During the procedure, EAC skin was protected with the cottonoid (Fig. 1C). After obtaining the sample for histologic work up, a PZD (Piezosurgery $^{\circledR}$, Mectron S.p.A., Genoa, Italy) and the long osteoplasty circular insert tip (MP5 L, Mectron S.p.A.) (Fig. 2A) were used to remove the eroded surface, layer by layer with continuous saline irrigation. The use of this PZD provided a smooth cut surface (Fig. 2B). The EAC was widened for the full visualization of the TM. After repositioning the skin flaps, the EAC was packed with several pieces of antibiotics soaked absorbable gelatin compressed sponge (Gelfoam $^{\circledR}$, Pfizer, New York, NY, USA) (Supplementary Video 1). The histologic analysis confirmed a diagnosis of EACE. At a 3-month follow-up after surgery, the patient was asymptomatic and free from any complications or relapse (Fig. 1D).

\section{Case 2}

A 12-year-old female visited our clinic with hearing difficulty in her right ear. The endoscopy showed an irregularshaped EAC mass, of which all margins were firmly attached to the skin (Fig. 3A). The following TBCT revealed a $1.3 \mathrm{~cm}$ sized expansile mass-like lesion confined to the right bony EAC with subtle adjacent bony erosion (Fig. 3B). Suspecting an EACC, the EES using PZD was planned to remove the mass. Under general anesthesia, the chole sac around the destructed EAC was extirpated. The remaining granulation at the TM was also removed (Fig. 4C). The burring off the destructed EAC and the excavation of tissue using PZD to form a shallow shelving depression were performed. The perforated TM and the bare bone were reconstructed with acellular dermal matrix (MegaDerm ${ }^{\circledR}$, L\&C Bio Inc., Seongnam, South Korea). The EAC was packed with antibiotics soaked absorbable gelatin compressed sponge $\left(\right.$ Gelfoam $\left.^{\mathbb{B}}\right)$ and fibrin sealant (Tisseel ${ }^{\circledR}$, Baxter Healthcare Corp., Deerfield, IL, USA) (Supplementary Video 2). The histologic analysis confirmed a diagnosis of EACC. At a 3-month follow-up, the patient was free from any complications or relapse (Fig. 3D). 

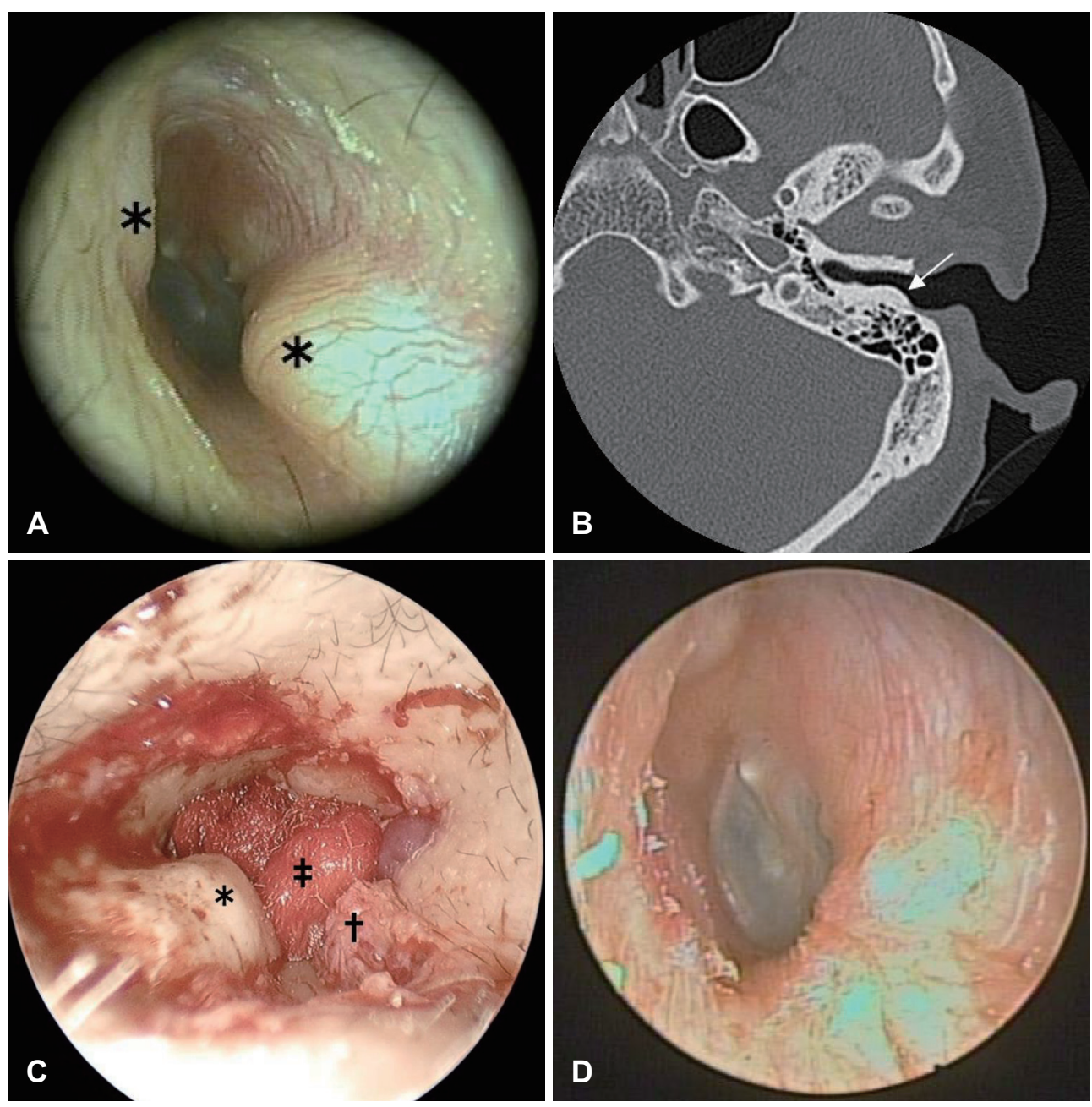

Fig. 1. Case 1 images of a 41-year-old male with external auditory canal exostosis. (A) Endoscopic image of left EAC. The photograph shows even-surfaced several masses $\left(^{*}\right)$ in the left bony EAC. (B) Computed tomography of temporal bone showing about 4 mm size bony protrusion (arrow) at anterosuperior wall of left EAC. This broad based bony proliferation is consistent with exostosis. (C) Procedure of the exostosis removal. After making several circumferential incisions from the apex to the base along the masses $\left({ }^{*}\right)$, skin flaps $(\dagger)$ were elevated as laterally based flaps for the lateral surface of the each masses and medially based flaps (t) for the medial side. In the procedure, EAC skin was protected with the cottonoid ( $)$. (D) Endoscopic image of left EAC. At 3-month follow-up, the patient was asymptomatic and free from any complications or relapse. EAC: external auditory canal.
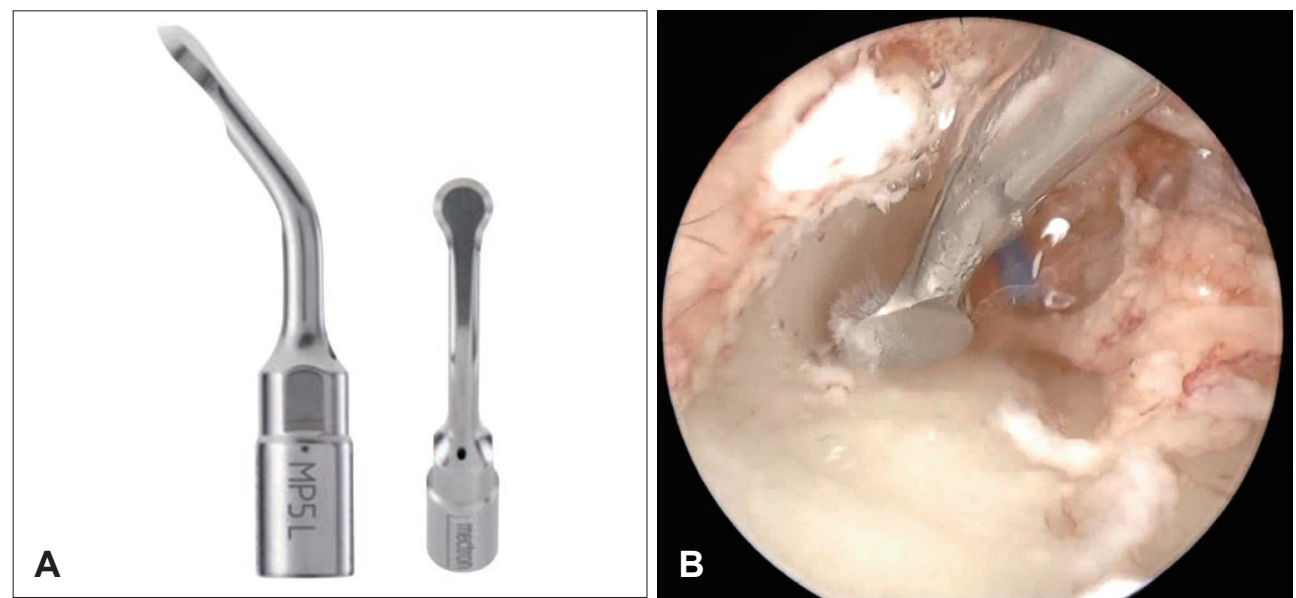

Fig. 2. The specific insert used in the surgery. (A) The long osteoplasty circular insert MP5 L (0.8 mm thickness; Mectron S.p.A.). (B) The use of this piezoelectric device provided a smooth cut surface. 

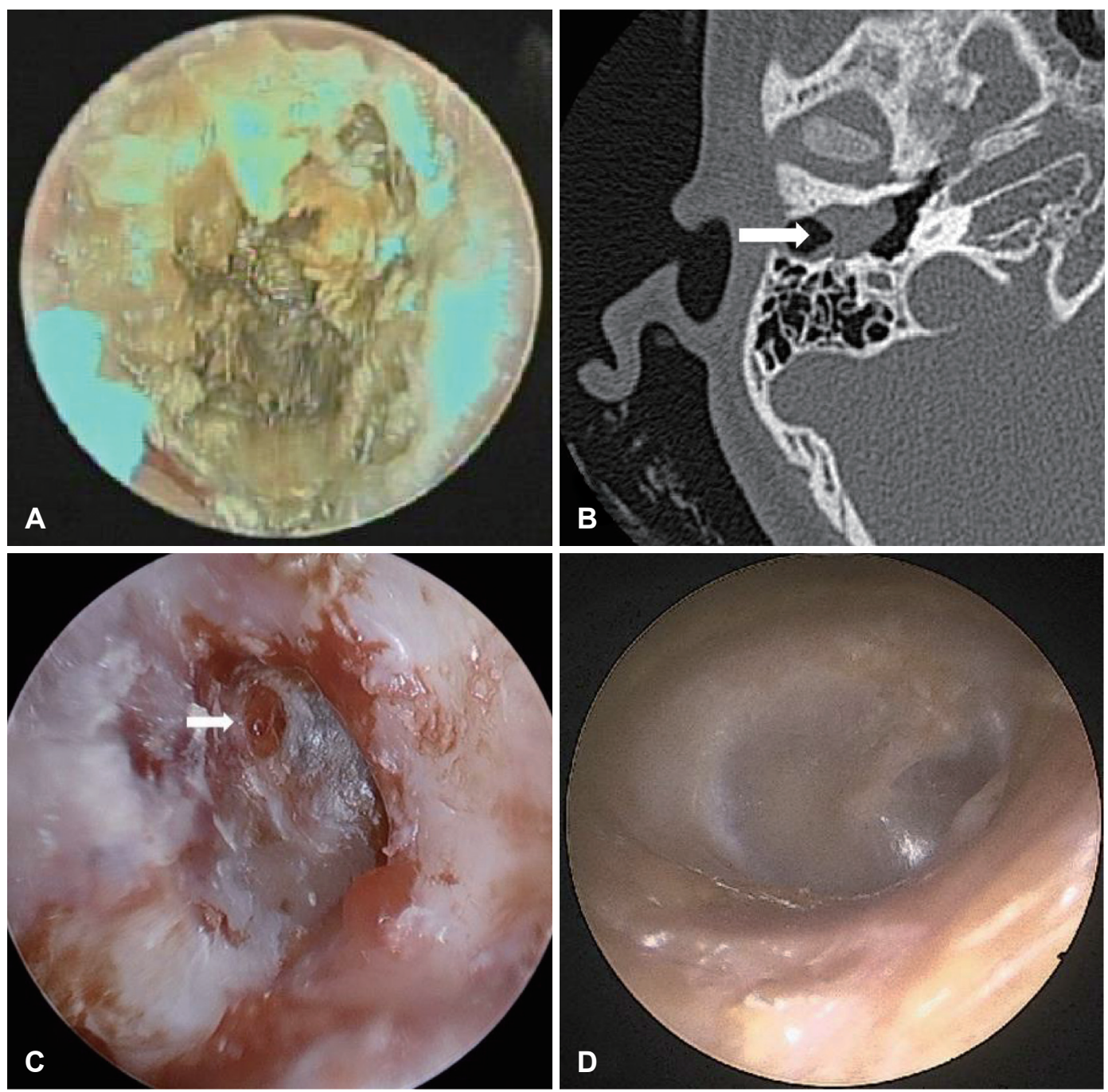

Fig. 3. Case 2 images of a 12-year-old female with external auditory canal cholesteatoma. (A) Endoscopic image of right EAC. The photograph shows an irregular-shaped EAC mass with all margins attached to the skin. (B) Computed tomography of temporal bone showing a $1.3 \mathrm{~cm}$-lengthened expansile mass-like lesion (arrow) confined to the right bony EAC with subtle adjacent bony pressure erosion. (C) Endoscopic image of the site of granulation at right tympanic membrane (arrow) during surgical procedure. (D) Endoscopic image of right EAC at 3-month follow-up after surgery. The patient was asymptomatic and free from any complications or relapse. EAC: external auditory canal.

\section{Case 3}

A 15-year-old male patient visited our clinic with right hearing disturbance. The endoscopy revealed a yellowish protruded irregular-shaped mass attached to the TM (Fig. 4A). The TBCT showed a homogenous soft tissue mass at the medial end of the right EAC with bone erosion (Fig. 4B). As in case 2 , the operation was performed with above-mentioned materials in the same manner except that the defect was reconstructed with sliced cartilage and perichondrium (Fig. 4C). The pathology report confirmed the mass to be an EACC. At a 2-month follow-up, the endoscopy showed that the TM and EAC were all in well healing status (Fig. 4D).

\section{Discussion}

In the 20th century, technology of otology has been advanced in terms of instrumentation, visualization and intraoperative nerve monitoring. The developments of the microscope, endoscope and surgical drills are representative exemples. ${ }^{6}$ After dentists had applied ultrasound technology as a cutting tool, thoracic surgery was the first department in medicine to use the ultrasound device in 1972. However, insufficient power of the original ultrasonic instrument inevitably led to the macrovibration and excessive heat production causing bony necrosis. ${ }^{7)}$ To overcome such problems, the PZD, a system with microvibrations, was developed. This relatively low frequency 

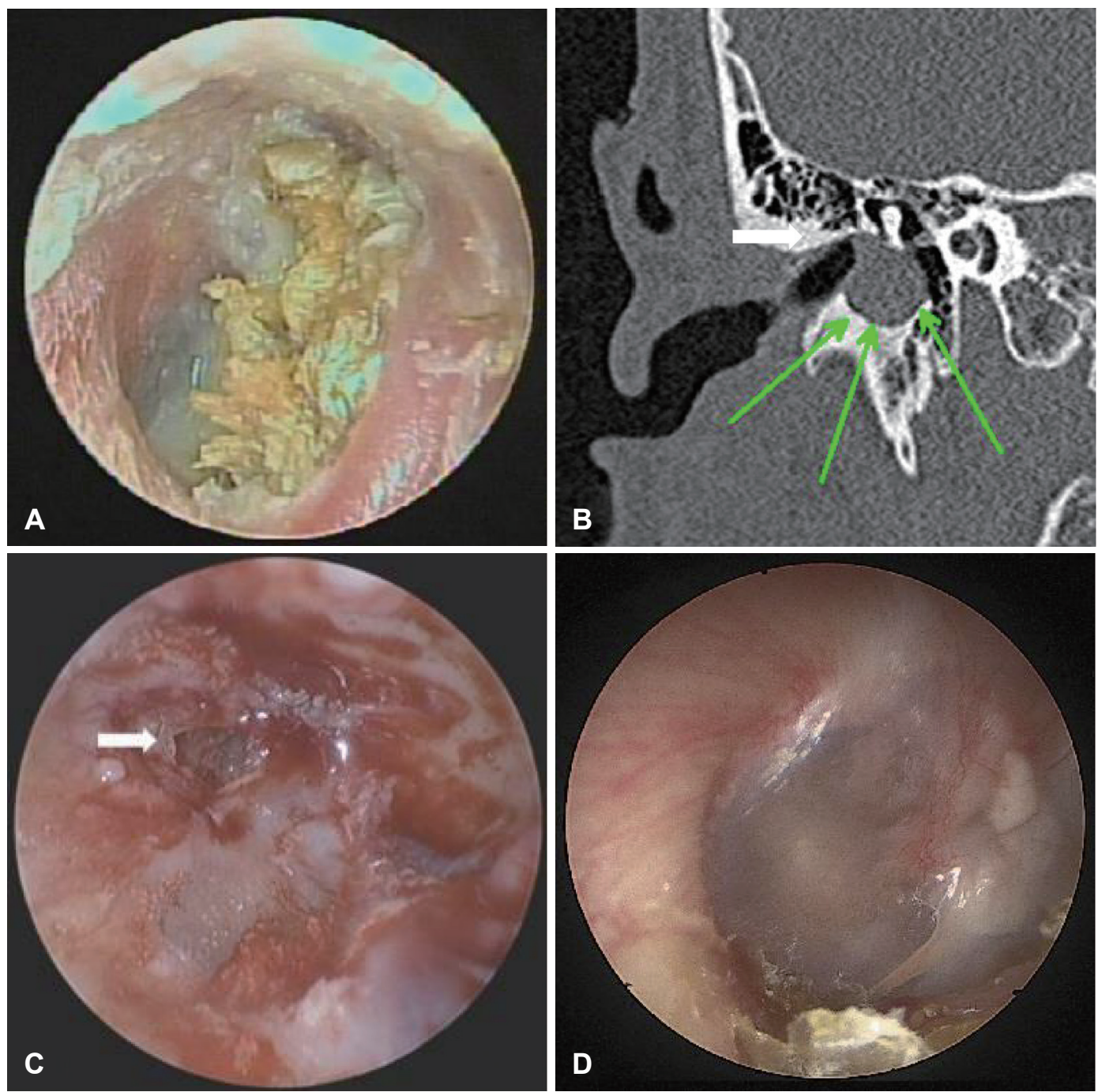

Fig. 4. Case 3 images of a 15-year-old male with external auditory canal cholesteatoma. (A) Endoscopic image of right EAC. The photograph shows a yellowish protruded irregular-shaped mass attached to the TM. (B) Computed tomography of temporal bone showing a homogenous soft tissue mass (white arrow) at the medial end of right EAC with bone erosion (green arrows). (C) Endoscopic image of right TM after EAC granulation msss removal. The chole sac at the destructed EAC and the remaining granaluation at the TM (arrow) were also removed using piezoelectric device. (D) Endoscopic image of right EAC at a 2-month follow-up after surgery. Both TM and EAC were in healing status and the patient was free of any symptoms. EAC: external auditory canal, TM: tympanic membrane.

$(24-36 \mathrm{kHz})$ device exclusively acts on the mineralized tissue, not influencing the surrounding soft tissues such as skin and nerves.

The term of piezo derives from Greek, meaning 'to squeeze or press. ${ }^{\text {,8) }}$ Certain ceramics and crystals contract or expand when an electric current is passed across them, causing oscillation. ${ }^{8)}$ The microvibrations make the device easy to handle and enhance the tactile control, making it possible to remove the mineralized tissue layer by layer with precision. ${ }^{4,8)}$ When the device loses contact with the bone accidentally, the cutting head is programmed to stop immediately. ${ }^{4)} \mathrm{PZD}$ converts just $30 \%$ of energy into heat, so remaining $70 \%$ is transformed into cutting power. ${ }^{9)}$ The integral peristaltic saline pump enables cooling of the tip, simultaneously removing debris from the operation field.

Many studies have also revealed that bone healing is improved after piezoelectric cutting at an early stage. ${ }^{10)}$ In animal studies of PZD, initial healing was faster and caused less epineural damage, compared to the conventional bur. ${ }^{11)}$ By avoiding coagulative necrosis at the bony margin, ${ }^{7)}$ there is less chance of vascular occlusion or blood flow disruption. ${ }^{12,13)}$

The microvibrations also make it possible to avoid inner ear damage. The frequency of ultrasound is greater than the upper limit of normal human hearing. The audiologic results verify the safety of the PZD in regard to hearing. ${ }^{4,8,10,14)}$

Nevertheless, our impression was that the PZD removed the 
bone slightly slower than the conventional bur. This is consistent with others' studies. ${ }^{14)}$ The operative time itself was $35 \%$ longer with PZD compared to a conventional bur. ${ }^{15)}$ However, when considering the effort of a surgeon to protect skin or soft tissue, the time required for addition skin graft, and the delayed healing by traditional drill, it is likely that there is in fact more merits in PZD.

EACE and EACC can be managed surgically if EAC obstruction or symptoms arise. In our case series, removing symptomatic EACE and EACC with the PZD was safe and effective approach. The minimal bleeding, lack of damage to the EAC skin and reduction of postoperative complications highlight the safety of EES with PZD. Such advantages make PZD an ideal tool to use especially at the borders between soft and hard tissues in cases of EACE or EACC.

\section{Supplementary Video Legend}

Video 1. After obtaining the sample for histologic work up, a piezoelectric device (PZD) (Piezosurgery ${ }^{\circledR}$, Mectron S.p.A., Genoa, Italy) and the long osteoplasty circular insert tip were used to remove the eroded surface, layer by layer with continuous saline irrigation. The use of this PZD provided a smooth cut surface.

Video 2. The burring off the destructed external auditory canal and the excavation of tissue using a PZD to form a shallow shelving depression were performed.

\section{Supplementary Materials}

The Data Supplement is available with this article at https://doi. org/10.3342/kjorl-hns.2020.01109.

\section{Acknowledgments}

None.

\section{Author Contribution}

Conceptualization: Jeong Hwan Choi. Data curation: Jeong Hwan Choi, Chan Young Lee. Formal analysis: Jeong Hwan Choi, Seung Ho Kim. Investigation: Jeong Hwan Choi. Methodology: Jeong Hwan Choi. Project administration: Jeong Hwan Choi. Supervision: Jeong Hwan Choi. Validation: Jeong Hwan Choi. Visualization: Jeong Hwan Choi, Chan Young Lee. Writing - original draft: Jeong Hwan Choi, Chan Young Lee. Writing-review \& editing: Jeong Hwan Choi, Chan Young Lee.

\section{ORCIDs}

Jeong Hwan Choi https://orcid.org/0000-0001-7348-9861
Chan Young Lee https://orcid.org/0000-0002-7384-2714

Seung Ho Kim https://orcid.org/0000-0002-3588-0963

\section{REFERENCES}

1) DiBartolomeo JR. Exostoses of the external auditory canal. Ann Otol Rhinol Laryngol Suppl 1979;88(6 Pt 2 Suppl 61):2-20.

2) Owen HH, Rosborg J, Gaihede M. Cholesteatoma of the external ear canal: Etiological factors, symptoms and clinical findings in a series of 48 cases. BMC Ear Nose Throat Disord 2006;6:16.

3) Shapira Y, Migirov L, Kronenberg J. Facial nerve decompression. Harefuah 2006;145(8):557-60, 632.

4) Salami A, Dellepiane M, Salzano FA, Mora R. Piezosurgery in the excision of middle-ear tumors: Effects on mineralized and nonmineralized tissues. Med Sci Monit 2007;13(12):PI25-9.

5) Puttasiddaiah PM, Browning ST. Removal of external ear canal exostoses by piezo surgery: A novel technique. J Laryngol Otol 2018;132(9):840-1.

6) Salami A, Mora R, Mora F, Guastini L, Salzano FA, Dellepiane M. Learning curve for Piezosurgery in well-trained otological surgeons. Otolaryngol Head Neck Surg 2010;142(1):120-5.

7) Chapple IL, Walmsley AD, Saxby MS, Moscrop H. Effect of instrument power setting during ultrasonic scaling upon treatment outcome. J Periodontol 1995;66(9):756-60.

8) Vercellotti T, Dellepiane M, Mora R, Salami A. Piezoelectric bone surgery in otosclerosis. Acta Otolaryngol 2007;127(9):932-7.

9) Dellepiane M, Mora R, Salzano FA, Salami A. Clinical evaluation of piezoelectric ear surgery. Ear Nose Throat J 2008;87(4):212-3, 216.

10) Gleizal A, Bera JC, Lavandier B, Beziat JL. Piezoelectric osteotomy: A new technique for bone surgery-advantages in craniofacial surgery. Childs Nerv Syst 2007;23(5):509-13.

11) Metzger MC, Bormann KH, Schoen R, Gellrich NC, Schmelzeisen R. Inferior alveolar nerve transposition--an in vitro comparison between piezosurgery and conventional bur use. J Oral Implantol 2006;32(1):19-25.

12) Vercellotti T, Nevins ML, Kim DM, Nevins M, Wada K, Schenk $\mathrm{RK}$, et al. Osseous response following resective therapy with piezosurgery. Int J Periodontics Restorative Dent 2005;25(6):543-9.

13) Cho YS, Hong SD, Chung KW, Hong SH, Chung WH, Park SH. Revision surgery for chronic otitis media: Characteristics and outcomes in comparison with primary surgery. Auris Nasus Larynx 2010;37(1):18-22.

14) Lenhardt ML. Ultrasonic hearing in humans: Applications for tinnitus treatment. Int Tinnitus J 2003;9(2):69-75.

15) Spinelli G, Lazzeri D, Conti M, Agostini T, Mannelli G. Comparison of piezosurgery and traditional saw in bimaxillary orthognathic surgery. J Craniomaxillofac Surg 2014;42(7):1211-20. 